\title{
Uma reflexão sobre a importância de um festival gastronômico como recurso turístico: um estudo do festival da lula em Arraial do Cabo (RJ)
}

Recebido em 03.06.2016. Aprovado em 20.11.2016 Avaliado pelo sistema double blind review

\author{
Alexandre Assunção das Neves \\ alexandreaneves@hotmail.com \\ Universidade Federal Fluminense - Niterói - RJ
}

\begin{abstract}
Resumo
O presente artigo apresenta a problemática da viabilidade do uso de um festival gastronômico como um atrativo turístico, demonstrando como exemplo o Festival da Lula que acontece anualmente no município de Arraial do Cabo, no Estado do Rio de Janeiro. Para este trabalho, foram feitos levantamentos bibliográficos que abordassem a atividade turística e o patrimônio da gastronomia, além da parceria entre ambos. Além disso, foram utilizados métodos de investigação de natureza qualitativa através da aplicação de formulários de pesquisa e entrevistas semiestruturadas, realizadas com a comunidade local, visitantes e os principais agentes sociais participantes da organização deste festival. Como resultado, infere-se que uma região que conta com uma gastronomia rica pode apropriar-se dela como um novo recurso na geração de empregos e divisas e, consequentemente, melhorar a qualidade de vida de seus habitantes.
\end{abstract}

Palavras-chaves: Turismo. Turismo Gastronômico. Festival Gastronômico. Gastronomia. Festival da Lula.

\begin{abstract}
This study presents the problematic of the viability of using gastronomy as a tourist attraction showing as an example the Festival of Lula that happens yearly at the town of Arraial do Cabo. To this work, it was made a literature review involving the partnership between the tourism activity and the heritage of gastronomy. Moreover, it was used methods of qualitative research through application of formularies and semi-structured interviews with local community, visitors and social agents participating at the organization of this festival. As result, it was noticed that a local that accounts with a rich gastronomy, can appropriate of it as a new resource capable of generating jobs and economic benefits and, consequently, improve the quality of life of its inhabitants.
\end{abstract}

Key Words: Tourism. Gastronomic Tourism. Festivals. Festival of Lula.

\section{Introdução}

A presente pesquisa versa sobre a importância do turismo gastronômico para o planejamento adequado da atividade turística como premissa possível para que os destinos turísticos possam proporcionar um meio mais sustentável no modo de vida de uma comunidade local, em termos econômicos, culturais e sociais.

A abordagem do tema também pretende mostrar que a implementação da gastronomia, um bem imaterial que aos poucos vem ganhando espaço como mais um tipo de atrativo turístico potencial, tem a capacidade de auxiliar na revitalização e valorização da identidade cultural. Nesse caso, pode ser considerado como um recurso inovador, na medida em que consegue romper as barreiras de estilos de vida globalizados e conhecimentos padronizados que as sociedades têm vivido há algumas décadas. 
O turismo gastronômico tem como ferramenta essencial para sua promoção os festivais e eventos gastronômicos, que divulgam comidas e bebidas tradicionais atraindo, significativamente, pessoas que enxergam os alimentos como algo mais do que a satisfação de uma necessidade fisiológica, a busca pelo prazer.

A união entre a gastronomia e o turismo já é existente no município de Arraial do Cabo, sendo assim, a intenção dessa pesquisa consiste em investigar uma comunidade que já se vale do uso da gastronomia como atrativo turístico identificando quais mudanças ocorreram desde sua fundação e descrever, principalmente, até que ponto o turismo gastronômico é relevante para o crescimento do turismo local.

$\mathrm{O}$ pesquisador acredita que o estudo do tema será útil para esclarecer e conscientizar aos órgãos públicos e privados, assim como a comunidade local, que uma região onde conta com uma gastronomia rica, porém inutilizada, pode apropriar-se dela como um novo recurso na geração de empregos e divisas e, consequentemente, melhorar a qualidade de vida de seus habitantes.

Sendo assim, propõe-se com este trabalho encontrar resposta para a seguinte questão: Qual vem sendo a contribuição do Festival da Lula para o desenvolvimento do município de Arraial do Cabo? Como base empírica, será analisado o Festival da Lula, um evento gastronômico que ocorre no município de Arraial do Cabo, descrevendo as transformações que foram provocadas na cidade a partir da utilização de sua gastronomia habitual neste evento.

A partir desta problemática, o objetivo geral deste trabalho consiste em investigar o potencial da gastronomia como um recurso para a atividade turística e apresentar o Festival da Lula de Arraial do Cabo como produto turístico específico de uma comunidade local. Tem como objetivos específicos: registrar o surgimento e as modificações e inovações do festival no decorrer de suas edições; investigar a motivação dos participantes para a realização do Festival da Lula e identificar os fatores que levaram um prato local a ser reconhecido e transformado em um evento turístico e enumerar os resultados promovidos pelo Festival da Lula como atrativo turístico do município de Arraial do Cabo.

Como pressuposto inicial, acredita-se que a promoção de festivais gastronômicos como atrativo cultural pode significar uma diversificação na oferta turística e contribuir para os impactos socioeconômicos e culturais positivos, se bem explorados pelas comunidades locais.

Através das preleções destas pessoas, puderam-se obter respostas para as indagações presentes neste trabalho como: a composição da estrutura e do grau de participação dos associados ao festival, a motivação dos visitantes e o quão proveitoso este evento gastronômico se torna para o desenvolvimento do turismo no município de Arraial do Cabo.

\section{A construção do Festival e o grau de participação dos principais agentes sociais}

Para que um festival aconteça e possa ser apreciados pelos futuros convidados, os organizadores devem se reunir para decidirem de que forma o evento será exposto a essas pessoas, fazendo parte da proposta de planejamento em conjunto para atender a necessidade de todos os envolvidos, como argumentado por Hall (2001) no primeiro capítulo.

Nos dias de hoje, aparentemente temos visto que a estrutura do local pode facilitar o entendimento sobre 0 significado de um festival, demonstrar qual o serviço ou produto será oferecido e até mesmo o tipo de público adequado para frequentá-lo.

Será visto a seguir quais agentes sociais fazem parte de toda a trajetória do Festival da Lula e o que cada um se propunha a fazer na construção e composição do festival.

De acordo com o secretário de turismo, Sr. Marco Simas, os agentes sociais participantes do festival são basicamente formados pela Associação de Pescadores de Arraial do Cabo (APAC) e a Secretaria de Turismo. A APAC foi o órgão fundador do festival que, recentemente passou a contar com o apoio da prefeitura. 
Há três anos, a Secretaria de Turismo vem se envolvendo com o festival em parceria com a APAC, entidade organizadora do festival. Sua equipe técnica, composta por seis bacharéis em turismo, se divide em equipes, cada qual com uma função diferente no desenvolvimento da atividade turística do município: planejamento, eventos e administração da secretaria. Após reconhecer o potencial do Festival da Lula, foram oferecidos aos pescadores que realizavam o evento uma estrutura diferente para o festival composto por palco, shows, tendas, tablado, além de propostas de reorganização do espaço físico e uma maior divulgação. Como resultado, criouse um ambiente mais adequado para promover o festival, que antes era impedido devido ao incômodo, seja da poeira quando realizado nas areias da praia ou pela fumaça das cozinhas ao redor.

A Secretaria de Turismo do município também contribui para o desenvolvimento do festival criando uma programação musical durante a festa, tentando sempre manter uma diversidade de estilos e harmonias de maneira intimista. Já os pescadores (APAC) ficam responsáveis pela venda das barracas alugadas pela Prefeitura para o comércio local de pratos a base de lula de maneira terceirizada para os interessados em participar do festival, seja habitante local ou não.

O evento é composto por 60 a 80 barracas, resultando de 30 a 40 para locação, já que são alugadas duas barracas por pessoa (uma fica na cozinha e a outra no atendimento). Ainda existem os gastos com contratos e os cachês dos shows, som e luz, cadeiras e mesas. Com a venda das barracas, os pescadores permanecem com o dinheiro que é repassado para a APAC como uma forma da prefeitura ajudar a associação que atende aos pescadores locais na compra de materiais de pesca como lampião, querosene, rede, atendimento médico e odontológico, dentre outros benefícios.

No $12^{\circ}$ Festival da Lula, em 2010, o evento foi realizado com uma estrutura de 25 barracas padronizadas (8 em doações aos pescadores), e foram oferecidos a preço popular cerca de 25 pratos variados de lula. Quem esteve presente durante os cinco dias de evento, pôde ainda contar com uma programação diversificada composta por shows, exposições e artesanato local, além da saborosa gastronomia típica da região (DOCUMENTO EMITIDO PELO MEDIADOR DE PESCA, O SR. FRANCISCO NETO).

Segundo o secretário de turismo, já existem algumas propostas para aprimorar ainda mais o festival como a regulamentação dos vendedores presentes acreditando que, dessa forma, possam gerar melhorias principalmente no atendimento ao público e na higienização das barracas. Além disso, cita a probabilidade de promover um concurso entre os participantes para eleger o melhor prato a base de lula.

Com relação à participação da comunidade no festival, o secretario de turismo afirma que é total. Começando pela equipe da secretaria de turismo, todos moradores de Arraial do Cabo. A pesca da lula é realizada unicamente pelos pescadores do município e os moradores trabalham no festival pelo lado da colônia e do turismo, comercializando a lula para o festival, assim como seu prato local e, também frequentando o evento.

Porém, de acordo com o tesoureiro do Festival, Sr. Manuel Teixeira, são poucos os pescadores locais que participam do comércio de lula e de seus pratos nas barracas. Segundo ele, há uma falta de interesse por parte do povo cabista em participar do festival através da venda dos pratos a base de lula, apenas do próprio pescado. Um dos motivos seria o pouco lucro que o pescador poderia ter se estivesse vendendo seus produtos nas barracas do festival, ao invés de estarem pescando nesse mesmo horário e tendo a chance de barganharem um pouco mais.

Nesse caso, pode-se dizer que grande parte dos responsáveis pela venda dos produtos gastronômicos são pessoas provenientes de outros lugares e que já trabalham no ramo da gastronomia, deixando claro que a comunidade não se encontra inserida em todas as etapas.

A União das Entidades de Pesca e Aquicultura do Estado do Rio de Janeiro (UEPA) é uma entidade que também já ajudou na divulgação do Festival da Lula. O mediador de pesca, Sr. Francisco Neto, confirmou que a UEPA contribuiu ao elaborar uma carta de apresentação do evento que foi encaminhado para empreendedores, na perspectiva de conseguirem recursos para o festival. Também inseriram em alguns eventos atividades culturais como: corrida de canoas e futebol. 
Aos associados e patrocinadores que, após receberem carta de apresentação com o projeto do festival, desejarem também participar, receberão um recibo para abater no imposto de renda como incentivo a participação.

Desde a sua criação, o festival já contou com pequenos apoios de empresas como o Instituto Brasileiro do Meio Ambiente e dos Recursos Naturais Renováveis (IBAMA), o Serviço Brasileiro de Apoio às Micro e Pequenas Empresas (SEBRAE), a Petrobras, a Companhia Nacional de Álcalis (CNA), além dos serviços públicos de segurança e energia elétrica.

Como meios de divulgação do festival, as entidades utilizam a internet, principalmente o site oficial do município, rádio, TV local, carros de som e camisetas.

Como se pode observar, o Festival da Lula foi reconhecido como um evento duradouro ganhando 0 apoio da Prefeitura e de outras empresas, para que sempre pudesse ser realizado anualmente.

Esse ano, $014^{\circ}$ Festival da Lula foi realizado pela primeira vez na Orla Flávia Alessandra, inaugurada no ano passado, e contou com várias atrações locais e shows principais, além das diversas barracas de gastronomia a base de lula e outros frutos do mar.

O evento passou por mudanças de planejamento e estrutura ao longo dos anos. A seguir será visto o tipo de público que frequenta o festival e as razões para a visita dos turistas a festa.

\section{Motivação dos visitantes e os fatores críticos para o sucesso do Festival}

Atualmente, pode-se perceber que a qualidade que os festivais populares ao redor do mundo oferecem, implicam no crescimento do número de pessoas que passam a frequentá-los e, consequentemente, no seu sucesso. Do mesmo modo, aumentam as chances de repetição do evento até que, finalmente, consigam permanecer no calendário festivo de uma região que, de acordo com Meléndez (2001) apud Silva (2007, p. 29), é essencial para auxiliar na divulgação de datas e informações sobre o significado e conteúdo das festas.

No caso do Festival da Lula, as mudanças no planejamento e estrutura da festa foram acompanhadas dos diferentes públicos que já passaram pelo festival e os que visitam ultimamente.

Segundo o secretário de turismo, Sr. Marco Simas, as pessoas que mais frequentavam o Festival da Lula faziam parte do turismo de massa. Recentemente, este grupo foi sendo substituído pelos turistas que se hospedam nos hotéis e pelos habitantes dos municípios da região como: Cabo Frio, Búzios, São Pedro da Aldeia, Iguaba Grande e Rio das Ostras.

O festival tem atraído, desde 2009, um público de aproximadamente 25 ou 30 mil pessoas durante os cinco dias de evento. Esse aumento no fluxo de pessoas também foi acompanhado de uma diversidade de habitantes de outras regiões, estados ou mesmo de outros países (Secretaria de Turismo).

De acordo com o tesoureiro, Sr. Manuel Teixeira, de alguns anos pra cá o evento passou a ser conhecido ao redor do Brasil e também já atraiu turistas de outros países. "Nós tivemos a oportunidade de uns 6 anos atrás, de pessoas através da internet tentar se comunicar da Holanda, entendeu, da Inglaterra, dos Estados Unidos e aqui da Argentina, procurando saber a data do festival".

Através de um documento emitido pelo mesmo, de acordo com as pesquisas de alguns jornais de circulação local, no $14^{\circ} \mathrm{Festival}$ da Lula a estimativa de público gerado foi de sessenta mil pessoas, o maior dentre todos os festivais realizados, durante os cinco dias de festa, onde $93 \%$ desse total aprovou a realização do evento.

Segundo documento emitido pela secretaria de turismo:

O público-alvo do evento é composto de pessoas de ambos os sexos, pertencentes às classes $A, B, C, D$ e E, moradores de Arraial, de municípios vizinhos e de outros estados, pessoas de bom nível de escolaridade, 
apreciadoras e consumidoras de bens culturais e gastronomia, e que gostam de programas noturnos onde possam ao mesmo tempo ampliar seus horizontes culturais, conhecer pessoas e vivenciar experiências gastronômicas com total segurança em companhia de familiares e amigos (SECRETARIA DE TURISMO DE ARRAIAL DO CABO) .

O público descrito pode ser observado na definição feita por Plog, Mitchell e Hall (2003) apud Schlüter (2006, p. 154-156) sobre um dos tipos de consumidores dos produtos gastronômicos: os gourmets locais. Notam-se características semelhantes como o interesse em participar de eventos gastronômicos, frequentar restaurantes locais que ofereçam a comida típica da região e a busca pelo convívio social e conhecimentos de cunho cultural, que tendem a ser repassados e acrescentados à rotina habitual.

O Festival da Lula pode ser considerado um festival aberto ao público em geral observando a presença de jovens e adultos, solteiros e casados, divididos entre moradores, turistas ou visitantes que não pernoitam, mas suas programações estão sempre favorecendo um ambiente caseiro que atraia as famílias.

Dentro da tenda de $2000 \mathrm{~m}^{2}$ fica dividido família num lado e o pessoal jovem que gosta de ficar dançando, gosta de estar se divertindo. A família vem para degustar e o jovem fica do outro lado. Vem o jovem e a família no festival. Tem vários públicos (JOAQUIM DE CARVALHO).

Para confirmar o tipo de público apresentado pela Secretaria de Turismo, foram feitas entrevistas com sete pessoas que visitaram o 14\% Festival da Lula que ocorreu entre os dias 04 e 08 de abril de 2012.

A primeira entrevista foi realizada com uma moradora do município de 57 anos, casada, acompanhada pelo marido e pelo filho. Possui $2^{\circ}$ grau completo, trabalha como guia turística e ganha uma renda mensal entre $\mathrm{R} \$ 1636,00$ a $\mathrm{R} \$ 3270,00$. Participa todos os anos do festival que conheceu através dos amigos. Sua motivação para comparecer no evento está baseada no prestígio que os moradores devem ter com a própria cidade. Dos pratos típicos oferecidos, foi destacado o strogonoff de lula e de camarão, aprovando ambos os pratos. Seu tempo de permanência no evento são de pelo menos 2 dias. Sobre o festival, a moradora afirma que esse foi 0 melhor ano do evento, se comparado aos anos anteriores, destacando mudanças na aparência do festival como: limpeza e a localização atual. Sua participação em outras festas populares, assim como em festivais gastronômicos é positiva tanto em Arraial do Cabo como em outros municípios e estados devido, principalmente, as exigências da profissão de um guia de turismo. Seu gasto com a gastronomia do festival no dia foi de $\mathrm{R} \$ 70,00$. A gastronomia foi citada como o melhor dos serviços oferecidos pelo festival. Por fim, foi declarado não haver necessidade de melhorias nesse último festival já que acontece em um ambiente amplo, limpo, tornando-o mais familiar e, por isso, recomendaria para outras pessoas.

A segunda entrevista foi realizada com um morador de João Pessoa (PB) de 25 anos, casado, acompanhado de esposa, filho e primos. Possui $2^{\circ}$ grau completo, marítimo e com uma renda mensal entre $R \$ 1636,00$ a $\mathrm{R} \$ 3270,00$. Está vindo pela segunda vez no festival que conheceu através dos familiares. 0 motivo de sua visita está relacionado ao tempo de férias do trabalho. Dos pratos típicos oferecidos, foi destacada a lula à dorê. Foi confirmado o comparecimento nos cinco dias do evento e ainda afirma que esse ano o festival superou suas expectativas devido a melhoria de localização e organização. Sua participação em outras festas populares e festivais gastronômicos é positiva por gostar de explorar e conhecer novas culturas. Seu gasto com a gastronomia no festival foi de $R \$ 60,00$ e, com a viagem, em torno $R \$ 1500,00$, sendo seu maior gasto referente ao meio de transporte (avião) e pernoite em casa de parentes/amigos. Sua visita a Arraial do Cabo também ocorre em épocas de Natal e Ano Novo. Dos pontos turísticos visitados, foram destacados as praias e o Pontal do Atalaia. $\mathrm{O}$ atendimento se destacou como o melhor componente de todo o festival. $\mathrm{O}$ ambiente familiar fez com que aumentasse sua intenção de retornar e de recomendar o festival para outras pessoas. Também não foi visto a necessidade de melhorias.

A terceira entrevista foi realizada com um morador do Rio de Janeiro (RJ) de 24 anos, solteiro, acompanhado pela namorada. Possui $2^{\circ}$ grau completo, trabalha como técnico de automação ganhando uma renda mensal a partir de $\mathrm{R} \$ 3270,00$. Está vindo pela segunda vez ao evento que conheceu através da televisão. 0 motivo da sua visita também está relacionado ao tempo de férias do trabalho e curiosidade em conhecer o festival. Dos pratos típicos oferecidos foi destacada a lula à dorê. Seu tempo de permanência no evento será de um dia. Sua 
participação em outras festas populares é positiva devido aos momentos de lazer e cultura proporcionados por esses eventos, porém o Festival da Lula foi o primeiro festival gastronômico visitado. Seu gasto com a gastronomia do festival foi de $R \$ 70,00$ e, com a viagem, em torno de $R \$ 3000,00$ sendo seu maior gasto referente à pousada em que pernoita. 0 meio de transporte utilizado para chegar a Arraial do Cabo foi o carro próprio. $O$ verão foi citado como a época em que mais visita a cidade. Dos pontos turísticos visitados, foram destacadas as praias, o farol e a Gruta Azul. as $\mathrm{O}$ bom atendimento e comida típica, além da organização e do espaço suficiente para comportar os visitantes foram citados como os componentes do festival de melhor qualidade. A intenção de voltar e recomendar o festival é existente devido a sua peculiaridade como um evento gastronômico a base de lula. De sugestão, foi recomendado um aumento do espaço para exposição do artesanato local.

A quarta entrevista foi realizada com um morador de Rosario (ARG) de 38 anos, casado, acompanhado pela esposa. Trabalha na área da medicina e possui uma renda mensal a partir de $R \$ 3270,00$. Está vindo pela primeira vez ao festival que conheceu através dos comentários feitos pelos residentes. A razão principal para sua visita está relacionada ao conhecimento da gastronomia local. Dos pratos típicos oferecidos destacam-se o strogonoff de lula e a lula à dorê e seu tempo de permanência no evento será de dois dias. Sua participação em outras festas populares e festivais gastronômicos é positiva porque proporcionam a chance de vivenciar novas experiências através das diferentes culturas. Seu gasto com a gastronomia do festival foi de $R \$ 60,00$ e, com a viagem, em torno de $\mathrm{R} \$ 2000,00$ sendo seu maior gasto referente ao transporte (avião). Seu pernoite ocorreu em uma pousada local e é a primeira vez que visita a cidade. As praias e ilhas ao redor do município foram os atrativos frequentados pelo visitante. A comida típica foi considerada o melhor componente do festival e junto ao clima se tornaram as razões para que possam retornar futuramente. Já o ambiente familiar e a hospitalidade fizeram parte dos motivos para recomendação da festa a outras pessoas. Mais uma vez, nenhuma sugestão para a melhoria do festival se fez necessária.

A quinta entrevista foi realizada com um morador de Porto Alegre (RS) de 32 anos, casado e acompanhado de seis amigos. Possui o $3^{\circ}$ grau completo, trabalha como empresário e ganha uma renda mensal a partir de $\mathrm{R} \$ 3270,00$. Está vindo pela primeira vez ao evento que conheceu através dos amigos. A razão principal para a visita está relacionada à curiosidade, em saber como era o festival, uma vez que já estava no município. 0 prato típico experimentado foi a lula à dorê. Seu tempo de permanência no evento será de um dia. Sua participação em outras festas populares e festivais gastronômicos é positiva por motivos de explorar novas culturas e conhecer as festas locais. Seu gasto médio com o festival foi de $R \$ 150,00$. Deste valor, $R \$ 100,00$ pertenceram aos gastos com a gastronomia. Os gastos com a viagem foram de $\mathrm{R} \$ 3000,00$ com o maior gasto relacionado à comida. Seu pernoite ocorreu em um hotel local e sua chegada ao festival foi através de um carro alugado. É a primeira vez que visita a cidade e até então chegou a realizar o passeio de barco ao redor das praias. Declarou não ter gostado do festival devido ao mal atendimento que the foi oferecido, alegando que os residentes locais não estão preparados para oferecer este tipo de serviço. Por esse motivo, disse não voltar ao festival ou mesmo recomendá-lo para outras pessoas caso este problema não seja resolvido. Por fim, afirmou que a informalidade vem prejudicando cada vez mais o desenvolvimento do turismo no Rio de Janeiro e sugere que os eventos sejam mais organizados e fiscalizados e acabe com essa falta de profissionalismo nos atendimentos oferecidos não só no festival como em todo o estado.

A sexta entrevista foi realizada com uma moradora da Argentina, de 40 anos casada e acompanhada pelo marido. Possui $03^{\circ}$ grau completo, trabalha como docente, ganhando uma mensal a partir de $\mathrm{R} \$ 3270,00.0$ motivo de estar na cidade foi para visitar a uma amiga, que lhe apresentou o festival este ano. Permanecerá apenas um dia no festival e por falta de tempo, não foi possível provar nenhum prato típico. Visita mais as festas populares do que os festivais gastronômicos apenas por curiosidade. 0 gasto no festival foi de $\mathrm{R} \$ 50,00$ somente com as bebidas. Os gastos com a viagem foram de $\mathrm{R} \$ 3000,00$ sendo maior deles relacionado aos meios de hospedagem. O meio de transporte utilizado para chegar à cidade foi o ônibus. É a primeira vez que frequenta a cidade e dos atrativos foram visitadas as praias. A gastronomia e os espetáculos foram os 
componentes que mais Ihe agradaram no festival, por isso, deseja retornar a cidade e recomendá-la as pessoas nesta época do ano. Também não houve a necessidade de melhorias para o festival.

A sétima entrevista foi realizada com um morador de Minas Gerais, de 30 anos, solteiro, acompanhado pela namorada. Possui $03^{\circ}$ grau completo, trabalha como engenheiro florestal e ganha uma renda mensal a partir de $R \$ 3270,00$. Está visitando pela primeira vez o festival que conheceu através dos anúncios na estrada. Seu motivo de visita está ligado a momentos de lazer na cidade, porém afirma que o festival preencheu o roteiro feito pelo próprio visitante ao se tornar uma opção de lazer à noite. Como havia acabado de chegar ao festival, não provou nenhum prato típico até o momento, mas garante que voltará pelo menos mais um dia para poder desfrutar melhor do ambiente. Afirma que visita tanto as festas populares como os festivais gastronômicos por uma questão de tradição dos mineiros que apreciam bastante as culturas, destacando a gastronomia de outros lugares. Sua estimativa de gasto com o festival está em torno de $R \$ 100,00$. Como o meio de transporte utilizado para chegar à cidade foi o carro próprio, seu maior gasto na viagem foi com o meio de hospedagem. Frequenta a cidade pela primeira vez e já visitou as praias através dos passeios de barco. Acredita-se que a música será o componente mais apreciado do festival e garante retorno e recomendação as outras pessoas, pois até 0 momento o ambiente está mais uma vez familiar.

Através da pesquisa qualitativa, que, segundo Flick (2009), podem descrever as ações das pessoas dependendo das situações em que se encontram, conseguiu-se obter as características pessoais, motivações e realização das viagens de alguns dos visitantes que frequentavam o Festival da Lula.

Além disso, foi possível fazer uma comparação com as respostas obtidas e descrever as relações em comum que existem entre esses turistas. Porém, lembrando que esta descrição foi feita apenas com os sete entrevistados, e por isso não pode ser generalizada a todos os participantes do festival.

Após a verificação dos resultados obtidos com os depoimentos pode-se constatar que os entrevistados apresentam características semelhantes, formada em sua maioria por pessoas casadas e acompanhadas de seus familiares. Geralmente, este tipo de público costuma aproveitar cada oportunidade para viajar em busca de lazer e recreação. Nesse caso, o destino turístico se tornará um elemento diferenciador ao proporcionar um momento de descanso e tranquilidade, por fim, uma fuga da rotina e do estresse consequentes do trabalho e da vida cotidiana.

A questão dos visitantes serem basicamente formados por pessoas que exercem algum trabalho remunerado, um grau escolar com ensino superior completo e faixa etária entre 30 e 40 anos, apontam que este é um público maduro, que se encontra com uma carreira profissional estabilizada e em que as possibilidades da realização de uma viagem se tornam mais fáceis, devido, principalmente, pelo fato de usufruírem de uma situação financeira média em um evento onde o gasto não precisa ser excessivo para a realização da viagem e satisfação de toda a família. A diversidade dos turistas com relação ao seu local de moradia demonstra a popularização do festival e sua expansão geográfica.

Os atrativos naturais são os recursos potenciais que fazem de Arraial do Cabo um lugar de paisagens únicas, além de belas. As praias ao redor do município foram destaques nos atrativos mais procurados pelas pessoas que se destinam ao local.

Deve-se ainda fazer uma observação quanto aos benefícios socioeconômicos que tais entrevistados também trouxeram para o turismo local como: o meio de hospedagem, destacado pela maioria como um dos serviços com o maior gasto na viagem; a comida nos estabelecimentos alimentícios; os serviços de locação de veículos e passeios de barco.

Ao fazer uma comparação dos resultados obtidos com os depoimentos pode-se constatar que existem algumas diferenças entre o tipo de público registrado pela Secretaria de Turismo do município com relação às pessoas entrevistadas. Desses turistas, nota-se que a motivação da viagem para a cidade está mais relacionada com os momentos de descanso e lazer oferecidos pelas belezas naturais do município, deixando o festival em segundo plano, como um complemento da visita a cidade.

Tais características condizem com o último tipo consumidor do turismo gastronômico apresentado por Plog, Mitchell e Hall (2003) apud Schlüter (2006, p. 154-156), os turistas gourmets. Estes visitantes se caracterizam 
como os "curiosos", ou seja, participam do evento gastronômico unicamente porque faz parte da experiência da viagem ou, nesse caso, significa um atrativo importante para o destino, mas não possui um interesse em especial pela gastronomia local.

Por outro lado, percebeu-se que o ambiente familiar que os agentes sociais tanto pregam está sendo percebido pelos visitantes. Observa-se que a maioria dos entrevistados faz parte do público que preza por permanecer em um espaço tranquilo e aconchegante ao fazer parte dos motivos essenciais para a recomendação e retorno dos mesmos sem que nada precise sofrer alterações. Nesse caso, é possível dizer que o novo ambiente pode gerar um sucesso ainda maior no festival.

O fato de o evento ser realizado na Semana Santa, um feriado também familiar, contribui para a prevalência desse tipo de visitante, além de auxiliar no aumento do fluxo de turistas na cidade.

O secretário de turismo, Sr. Marco Simas, afirma que o Festival da Lula possui certo respeito pelo feriado da Semana Santa, fazendo com as atividades realizadas durante o período do evento sofram alguns ajustes como a preocupação com o repertório do festival que procura sempre preservar um estilo "voz e violão", mantendo sempre um bom vínculo com o outro feriado e, nesse caso, com a Igreja Católica.

A nova operação do festival procura mudar, pouco a pouco, o perfil do turista que frequenta Arraial do Cabo. Como estratégia, a cidade está começando com alterações na programação dos eventos que ocorrem no município durante todo 0 ano.

Mas as mudanças na organização do festival por si só não são suficientes para explicar a expansão e notoriedade que vem apresentando nos últimos anos. No caso do festival popular, há sempre uma bagagem contendo história, costumes e hábitos que dão sentido para sua criação e desenvolvimento.

Conforme apontado anteriormente por Ribeiro (2002), uma festa popular significa um ambiente de socialização entre as pessoas com a possibilidade de aprendizagem sobre a "experiência histórica" do outro, fenômeno que pode ser visto no Festival da Lula, de acordo com a secretaria de turismo:

Para o público-alvo, o evento representa a possibilidade de intensa sociabilidade e lazer, realizados com total segurança num dos cartões postais mais belos, charmosos e acolhedores do município, e de apreciar uma programação musical que prima pela diversidade e qualidade, buscando trazer para o Arraial do Cabo o mais variado possível gama de gêneros musicais, do choro aos rimos nordestinos (SECRETARIA DE TURISMO) .

Nesse caso, um festival popular deve representar a tradição local em sua totalidade como os produtos que serão apresentados, a decoração, estrutura, local. Para além disso, ser capaz de levar tal informação para quem ainda o desconhece através de divulgação em jornais, revistas e TV, panfletos sobre a história da cidade e sua ligação com a gastronomia.

Segundo Ribeiro (2002), são várias as manifestações culturais que podem ser expressas em uma festa popular. No que diz respeito ao Festival da Lula, essa manifestação ocorre através da exposição da gastronomia típica a base de um produto local, a lula.

Os frutos do mar são produtos essenciais que fazem parte da culinária dos moradores de Arraial do Cabo devido a sua abundância na região, sendo várias as opções de pratos preparados à base de lula como: lula ensopada, frita, gratinada, moqueca, pastel, risoto, strogonoff, panqueca, dentre outros.

Logo, pode-se afirmar que a gastronomia vendida no festival também faz parte dos hábitos alimentares da população local, excetuando-se a "lula com a tinta", que, segundo a moradora Maria Gomes, seria a lula inteira tirada da praia e que vai direto para o cozimento sem uma limpeza profunda para retirar seus resíduos. Existem também adaptações de algumas receitas mais comuns ou em conjunto com sabores de outros países como 0 escondidinho e o yakisoba de lula.

O Festival da Lula parece vir demonstrando uma grande importância como um evento social que dissemina sobre a cultura de seu povo e tem chamado uma atenção cada vez maior das pessoas ao ouvirem falar de sua 
existência. Resta saber se todo esse potencial pode tornar-se um atrativo capaz de causar um desenvolvimento da atividade turística no município e gerar os benefícios que podem ser vinculados ao fenômeno do turismo.

\section{Contribuições do Festival da lula para o desenvolvimento do município de Arraial do Cabo}

O Festival da Lula é um dos principais eventos que acontecem em Arraial do Cabo e faz parte da programação turística do município, fato que ocorre desde o primeiro evento, pois sempre esteve no propósito de seus idealizadores. Porém, pode-se constatar que, após a intervenção da Prefeitura em apoiar o festival através de uma reformulação e forte divulgação, conseguiu chegar ao patamar que hoje se encontra.

É importante ressaltar que sua grandeza nunca afetou as ideias originais da criação do festival, ou seja, seu âmbito cultural continua conservado. No entanto, vem contribuindo com notáveis benefícios para a cidade e sua população que, segundo a OMT (2001), são divididos em aspectos econômicos, culturais ou ambientais, contribuindo também com impactos no desenvolvimento da atividade turística de determinado lugar.

Os impactos econômicos podem ser observados como as formas diretas, indiretas e induzidas de relações comerciais, nesse caso, provocados pela atividade turística. Desse modo, apoiando-se nas observações dos entrevistados, podem ser considerados como impactos econômicos promovidos a partir do Festival da Lula para o município:

- $\quad$ Aumento e geração de renda e novos empregos temporários para a população local, acarretando, segundo Sr. Marco Simas, em torno de 150 ocupações, dentre os quais se destacam: garçons, cozinheiros, atendentes e outros.

- Maior fluxo de caixa para os empreendimentos turísticos: pousadas, hotéis, restaurantes;

- $\quad$ Aumento no comércio de mercadorias em estabelecimentos locais como: supermercados, farmácia;

- Geração de renda para os pescadores e familiares a partir da venda do pescado e aluguel das barracas;

- Possibilidade de lucro através do aluguel das casas dos moradores para os visitantes no período do Festival.

Quanto aos impactos socioeconômicos negativos, o Sr. Marco Simas, afirma não haver. Segundo o secretário, a única concorrência existente acontece entre as barracas do festival, pois existe um preço padrão para a venda dos produtos gastronômicos. Cada vendedor estipula o seu preço, o prato que será vendido e em que quantidade.

Pode-se perceber que o fluxo atual de visitantes no Festival da Lula tem gerado um ganho para quem busca se beneficiar das oportunidades que surgem a partir deste evento.

De acordo com o Sr. Manuel Teixeira, se todas as 30 barracas do festival forem vendidas, o evento já começaria com uma receita de $R \$ 30.000,00$, onde $R \$ 10.000,00$ seriam redistribuídos em forma de pagamento para as pessoas que trabalharam no festival mais os serviços de limpeza, segurança, energia e equipamentos. Nesse caso, o Festival ainda sairia com um lucro de $\mathrm{R} \$ 20.000,00$ para a Associação dos Pescadores.

Na própria venda do pescado para os comerciantes e visitantes da região, os pescadores podem conseguir uma renda elevada, pois conseguiriam vender grande quantidade de seus produtos pelo dobro do preço normal no período de realização do festival, segundo afirma o Sr. Francisco Neto.

Uma exposição mais detalhada dos custos com o material utilizado durante $012^{\circ}$ Festival da Lula em 2010 pode ser observada na tabela 1.

\begin{tabular}{l|l|c}
\hline Descrição & Unidade & Preço Total \\
\hline $\begin{array}{l}\text { Tenda de formato retangular } \\
\text { como cobertura piramidal com } \\
\text { dimensões de } 2.000 \text { metros }\end{array}$ & & $\mathrm{R} \$ 35.000,00$ \\
\hline
\end{tabular}




\begin{tabular}{l|c|c}
\hline $\begin{array}{l}\text { quadrado } \begin{array}{l}\text { bechamento e balcão. } \\
\text { ferracas }\end{array} \\
\end{array}$ & \\
\hline Palco, Som, lluminação. & $\mathrm{R} \$ 18.000,00$ \\
\hline Taxa de Energia. & & $\mathrm{R} \$ 9.000,00$ \\
\hline & & $\mathrm{R} \$ 9.000,00$ \\
\hline Aluguel de Mesas e Cadeiras & & $\mathrm{R} \$ 40.000,00$ \\
\hline Show - Cachê & 05 & $\mathrm{R} \$ 7.000,00$ \\
\hline Banheiro Químico & $\mathrm{R} \$ 15.000,00$ \\
\hline 1.000 Camisetas Estampada - & & $\mathrm{R} \$ 153.000,00$ \\
\hline Silk Screen & & $\mathrm{R} \$ 10.000,00$ \\
\hline Segurança & & \\
\hline Mídia & & \\
\hline Total Geral & & \\
\hline
\end{tabular}

Tabela 1 - Custos gerados pelo $12^{\circ}$ Festival da Lula em 2010.

Fonte: Elaboração própria a partir de Documento emitido pelo mediador de pesca Francisco Neto, 2012.

Através de estimativa feita pelo tesoureiro Manuel Teixeira, $013^{\circ}$ Festival da Lula, realizado em 2011, foi capaz de gerar uma receita total de $R \$ 24.000,00$ durante todo o evento, com despesas em torno de $R \$ 3.000,00$ resultando em um lucro de $\mathrm{R} \$ 21.000,00$.

Segundo o mesmo, no $14^{\circ}$ Festival da Lula, que ocorreu entre os dias 04 e 08 de abril de 2012, só o aluguel das barracas utilizadas no evento, seja para a comercialização dos produtos gastronômicos ou para a feira de artesanato, foi capaz de gerar uma receita equivalente a $\mathrm{R} \$ 27.350,00$. Das despesas, foi estimado um valor em torno de $\mathrm{R} \$ 17.198,60$ que corresponde aos gastos com equipamentos da festa, alimentação, mão de obra, suporte a algumas famílias de pescadores e outros. Sendo assim, o lucro gerado foi de $R \$ 10.151,40$.

Foram vendidos 10 toneladas de lula, 2 toneladas de filé de peixe, $600 \mathrm{~kg}$ de camarão e $400 \mathrm{~kg}$ de mexilhão. Infelizmente, não houve acesso ao lucro gerado pelos pescadores através da venda desses alimentos e dos produtos gastronômicos pelos comerciantes.

Sendo assim, não foi possível fazer uma comparação com o festival passado, já que o resultado apresentado não faz parte do lucro total da festa. Porém acredita-se que o valor tenha sido superior ao ano anterior, já que foi preciso uma quantidade maior de frutos do mar para comportarem ao número de visitantes desse ano, 0 maior dentre os festivais realizados. 
De acordo com o Sr. Marco Simas, o Festival também foi capaz de gerar alguns benefícios socioculturais ao município. Para a gastronomia local, por exemplo, além de torná-la conhecida e apreciada por visitantes das mais variadas localidades, tem sido preservada pela população residente que, em um primeiro momento, passou a ter um maior incentivo pela pesca e preparo das receitas tradicionais, resgatando as práticas habituais dos moradores da região.

No entanto, para o tesoureiro, Sr. Manuel Teixeira, a gastronomia oferecida pelo Festival tem uma importância maior para os turistas que ainda não a conhecem do que para a comunidade local, por fazer parte de seu cotidiano ao comentar que o motivo maior para participarem do festival seria o lazer e diversão, mas não necessariamente a comida. "[...] se eles não quiserem comer lula no festival, eles vão a qualquer restaurante aqui no Arraial do Cabo que eles vão conseguir a mesma coisa".

O atual ambiente familiar proporcionado pela festa impede qualquer intervenção negativa que possa modificar o seu real significado. Isso faz com que não ocorram fenômenos como a descaracterização e o choque cultural, geralmente provocado pelos turistas ao exporem seus costumes.

Em depoimento, o secretário de turismo Sr. Marco Simas afirma que a Prefeitura tem uma preocupação em passar adiante a tradição presente no festival para os futuros habitantes, mantendo fixa a ideia de que todo 0 ano possa acontecer 0 evento.

Do mesmo modo, o presidente da APAC, Sr. Joaquim Carvalho, esclarece que são feitos registros em áudio e vídeo para que seja mostrada futuramente a população que terá o dever de passar esse legado adiante.

Por fim, não compete ao Festival da Lula proporcionar algum benefício ligado ao aspecto socioambiental. No entanto, existe todo um cuidado para que o mesmo não agrida o espaço utilizado. $O$ óleo é recolhido com 0 auxilio de uma ONG que trabalha com óleo reciclado, a limpeza do lugar e recolhimento das estruturas evitando deixar qualquer resíduo proveniente do festival.

De acordo com o Sr. Francisco Neto, nos primeiros festivais, assuntos como a importância da preservação das espécies e da reserva extrativista para manter os recursos marítimos foram abordados de forma a conscientizar os participantes do festival. $O$ entrevistado ainda sugere que a cidade deveria contar com uma melhor coleta de lixo seletiva e aumentar os espaços para estacionamento, evitando-se congestionamentos.

O Festival da Lula também apresenta alguns impactos no desenvolvimento do turismo em Arraial do Cabo uma vez que provoca a entrada de um número maior de turistas ao município. Esse aumento no fluxo de visitantes também beneficia os equipamentos turísticos existentes na região, caso que ocorre nos restaurantes e pousadas.

Segundo a Secretaria de Turismo, a estimativa sobre a taxa de ocupação dos hotéis no período de realização do festival foram as seguintes: 55\% em 2009, 60\% em 2010 e 2011.

De um modo geral, a Secretaria de Turismo calcula essas estimativas de ocupação hoteleira local nas épocas em que ocorrem os eventos da cidade. Porém os dados estatísticos da ocupação hoteleira desses outros eventos não foram obtidos e, por isso, não foi possível fazer uma comparação com as informações acima.

O secretário de turismo, Sr. Marco Simas, acredita que o sucesso do festival possa ajudar na imagem da cidade, transformando-se em um cartão postal para uma visita à Arraial do Cabo. E também de maneira política, no aperfeiçoamento da gestão e operação dos eventos da cidade.

Sendo assim, percebe-se que o Festival da Lula em si, mais os resultados alcançados pelo mesmo correspondem às expectativas dos entrevistados preenchendo ainda mais as porcentagens de ganhos para a cidade, seja de forma econômica, cultural, mas, principalmente, social.

\section{Considerações Finais}

A atividade turística é uma das áreas do conhecimento humano que mais cresce e se desenvolve gerando oportunidades variadas para atender as suas segmentações de mercado. Sendo alavancado pelo mundo 
globalizado, o turismo se tornou uma tendência mundial, fazendo parte quase que de uma obrigação da vida moderna.

O turismo, como atividade econômica vem ocupando uma posição bastante significativa na economia dos países que o utiliza como suporte para o desenvolvimento socioeconômico de cidades e regiões gerando melhores condições de sobrevivência para seus habitantes através da geração de renda e empregos diretos e indiretos.

Porém, para que determinada localidade possa lucrar a partir do turismo, faz-se necessário que a mesma apresente recursos potenciais que possam ser convertidos em futuros atrativos através de um processo de turistificação. Essa conversão acontece quando são apresentadas possibilidades de distinção que serão percebidas pelos futuros turistas.

A gastronomia local se enquadra nesse comportamento, pois pode oferecer momentos únicos aos visitantes através da oferta de alimentos com sabores tradicionais em um ambiente dinâmico e original tal como em forma de um festival popular.

Através da pesquisa realizada no Festival da Lula pode-se constatar que se trata de um atrativo turístico que realmente potencializa a atividade turística no município de Arraial do Cabo em todas as suas dimensões. Como pode ser observado no último capítulo deste trabalho, o evento tem ajudado a gerar fontes de renda para os moradores locais, a preservar um dos patrimônios culturais da cidade e, o maior dos benefícios, promover a cidade em outros municípios, estados e países.

Por fazer parte de um festival gastronômico que utilize a culinária do município como principal recurso, criouse um produto diferenciado na cidade, pois se trata de um bem imaterial local que, como não sendo característico de nenhum outro lugar, poderá sempre proporcionar uma experiência única para seus visitantes.

Nesse caso, o Festival da Lula pode desenvolver algumas funções como ser 0 atrativo principal para aqueles que procuram o segmento do turismo gastronômico ou de forma a complementar os demais produtos turísticos existentes na região gerando uma movimentação maior de turistas na cidade.

Ambas as funções puderam ser percebidas nas entrevistas com os visitantes que compareceram ao festival para prestigiar a comida típica ou por curiosidade em conhecer o evento enquanto visitavam a cidade.

Acredita-se que a nova data também garantiu o aumento no número de turistas à festa. Por fazer parte de um feriado prolongado, a Semana Santa se torna a época ideal até para que um público de outras regiões tenha a oportunidade de conhecer a cidade e explorá-la com mais tranquilidade.

Além disso, o feriado religioso é sempre movimentado por grande número de fiéis da religião católica ou mesmo "curiosos" que participam e assistem às missas e encenações tradicionais do evento. Outra tradição do feriado religioso que pode gerar benefícios para o evento é o costume de não comer carne vermelha durante a semana, mas os mesmos alimentos que fazem parte dos produtos do festival, como os frutos do mar.

Ao propor a realização de uma festa em um destino turístico, deve-se considerar a maneira como a manifestação cultural será apresentada visto que a população local não será mais o único membro participante, mas contará também com a intervenção dos turistas, dos planejadores do evento ou outras entidades, cada um com a sua visão sobre o que a festa deve lhe proporcionar.

É possível perceber que a medida que o Festival da Lula foi ganhando reconhecimento tanto sua organização quanto seu espaço tiveram de ser revistos para que o evento conseguisse atrair um número maior de visitantes através de divulgações e pudesse comportar em sua estrutura essa nova demanda.

Acredita-se que o turista vai sempre esperar pela melhor qualidade em todos os componentes que fizerem parte do festival, que muitas vezes significa a utilização de produtos e serviços atualizados e padronizados de forma a proporcionar mais conforto e segurança para as pessoas. 
No entanto, deve-se sempre focar no significado real da festa, como na gastronomia local, no caso do Festival da Lula. Ou seja, tentar transmitir ao máximo o valor de um bem imaterial que é desconhecido pelos não residentes e fazê-los vivenciar toda a experiência que a cultura de uma sociedade pode apresentar. Desse modo, volta-se a questão do planejamento sustentável que é capaz de gerar benefícios a todas as partes envolvidas.

Por fim, chega-se à conclusão de que uma gastronomia local bem administrada pode efetivamente tornar-se um atrativo turístico potencial para, no mínimo, auxiliar no desenvolvimento de determinado lugar em sua totalidade promovendo, acima de tudo, a qualidade de vida para seus moradores.

\section{Referências}

FLICK, Uwe. Introdução à pesquisa qualitativa. 3. ed. Porto Alegre: Artmed, 2009.

HALL, Colin Michael. Planejamento turístico: políticas, processos e relacionamentos. São Paulo: Contexto, 2001.

ORGANIZAÇÃO MUNDIAL DO TURISMO (OMT). Introdução ao turismo. São Paulo: Roca, 2001.

RIBEIRO, Cleodes Maria Piazza Julio. Festa e Identidade: como se faz a festa da uva. Caxias do Sul: EDUCS, 2002.

SCHLÜTER, Regina G. Turismo y patrimonio gastronômico: una perspectiva. 2. Ed. Centro de Investigaciones y Estudios Turísticos, CIET, 2006.

SILVA, Mauro Amancio da. Entrai - Encontro das tradições italianas, Festa popular - patrimônio cultural, lazer e turismo. Caxias do Sul, UCS, 2007. 161 p. Tese (Mestrado) - Programa de Pós-Graduação Mestrado em Turismo, Faculdade de Turismo, Universidade de Caxias do Sul, Caxias do Sul, 2007. Disponível em: <http://tede.ucs.br/tde_arquivos/3/TDE-2007-10-02T130309Z-

143/Publico/Dissertacao\%20Mauro\%20A\%20Silva.pdf>. Acesso em: 14 de fevereiro de 2011. 